\title{
Modificação do diâmetro de microcápsulas de poli(ureia-formaldeído) pelo uso de octanol
}

\author{
Modification of the diameter of microcapsules of \\ poly (urea-formaldehyde) using octanol
}

\author{
Sara Ferreira da Costa ${ }^{1}$, Ângela Graziela Lechinski da Luz de Andrade ${ }^{1}$, \\ Marcia Margarete Meier ${ }^{1}$, Sérgio Henrique Pezzin ${ }^{1}$
}

\begin{abstract}
${ }^{1}$ Programa de Pós-Graduação em Ciência e Engenharia de Materiais (PGCEM), Universidade do Estado de Santa Catarina (UDESC), Campus Universitário Prof. Avelino Marcante, S/N, CEP: 89.219-710, Joinville, Santa Catarina, Brasil. e-mail:sarafdcosta@hotmail.com, sergio.pezzin@udesc.br, marcia.meier@udesc.br
\end{abstract}

\section{RESUMO}

Em polímeros autorregeneráveis faz-se uso de cápsulas preenchidas com agentes cicatrizantes, cuja parede rompe em função de estímulo externo, liberando e selando as trincas nos materiais. Assim, esse trabalho teve como objetivo avaliar as possíveis mudanças na morfologia e diâmetro de microcápsulas (MC) de poli(ureiaformaldeído) (PUF) pela variação da concentração de octanol. Medidas de microscopia ótica (MO) e microscopia eletrônica de varredura com efeito de campo (FEGSEM) mostraram que o diâmetro das MC e a rugosidade da parede, associada com a formação de nanocápsulas na emulsão, aumentaram conforme a quantidade de octanol adicionada na síntese aumentou. As curvas termogravimétricas (TG) mostraram que as microcápsulas são mais estáveis termicamente comparadas a trabalhos da literatura. Concluiu-se que o uso do octanol contribui para a obtenção de MC de tamanho mais uniforme e com superfície mais lisa.

Palavras-chave: microcápsulas, poli(ureia-formaldeído), síntese, octanol.

\section{ABSTRACT}

In self-healing polymers, capsules filled with healing agents are used, whose walls rupture as a response to external stimulation, releasing and sealing the cracks in the materials. Thus, this work had as objective to evaluate the possible changes in the morphology and diameter of microcapsules (MC) of poly(ureaformaldehyde) (PUF) by variation of the octanol concentration used in the synthesis. Through the measurements with optical microscopy (OM) and scanning electron microscopy with field effect (FEGSEM), it was verified that the MC diameter and the wall roughness associated with the formation of nanocapsules in the emulsion increased as the amount of octanol added in the synthesis increased. Thermal analysis showed that the microcapsules synthesized this way are more thermally stable compared to those reported in the literature. It was concluded that the use of octanol contributes to obtaining MCs with a more uniform size and smoother surface.

Key words: microcapsules, poly(urea-formaldehyde), synthesis, octanol.

\section{INTRODUÇÃO}

Os materiais poliméricos são utilizados em uma larga variedade de aplicações, como partes estruturais de veículos, navios e aeronaves. No entanto, esses materiais poliméricos podem sofrer algum tipo de dano, como impacto, excesso de carga, ou torção, gerando uma trinca [1,2]. Assim, com o objetivo de detectar e reparar rapidamente uma trinca, sem contato manual ou por máquinas e reduzindo os custos com manutenção, pesquisadores estão desenvolvendo e aplicando microcápsulas para a autoregeneração de materiais poliméri$\cos [3,4]$.

O processo de regeneração nos materiais poliméricos é desencadeado por danos no material, em que a trinca gerada rompe as microcápsulas, liberando um material líquido chamado de agente de cicatrização. Esse agente de reticulação possui um grupo funcional compatível com a matriz polimérica. $\mathrm{O}$ espaço vazio criado pela trinca é, então, preenchido pelo agente de cicatrização, seguido pela formação de reticulação, restaurando as propriedades da matriz polimérica [5]. 
Os materiais mais utilizados como parede para as microcápsulas são a ureia-formaldeído (PUF) [6,7], melanina-formaldeído (MF) e melanina-ureia-formaldeído (MUF) [8]. Cápsulas produzidas por esses materiais possuem uma resistência mecânica adequada, permanecendo intactas na sua maioria, quando incorporadas na matriz polimérica; contudo, quando ocorre o dano no material, elas são facilmente quebradas deixando o 'agente de cicatrização' fluir para o plano da trinca [9].

A primeira resina epóxi a ter suas propriedades recuperadas através da autorregeneração foi descrita por White et al. [10]. Foi alcançada a recuperação de $75 \%$ da tenacidade à fratura com a incorporação de microcápsulas de poli(ureia-formaldeído) (PUF) preenchidas com diciclopentadieno (DCPD) e catalisador de Grubbs disperso na matriz polimérica. Quando ocorreu uma trinca no material, as microcápsulas se romperam e o DCPD foi liberado e, reagindo com o catalisador, iniciou a reação de polimerização fechando a trinca [10].

Muitos outros trabalhos utilizando microcápsulas começaram a ser realizados após a publicação do estudo de White et al. [10], principalmente utilizando microcápsulas de PUF. Porém, a força de ligação das microcápsulas com a matriz, a fração mássica de microcápsulas e a resistência mecânica das microcápsulas a serem incorporadas na matriz polimérica podem afetar as propriedades mecânicas do material regenerado [10-12]. Espuma, cápsulas quebradas e mal preenchidas também podem diminuir a estabilidade térmica e mecânica de um material polimérico [13]. Assim, algumas variações nos parâmetros de síntese podem melhorar a morfologia da cápsula evitando a diminuição das propriedades do polímero que será fabricado.

Brown et al. [11] observaram que o diâmetro médio das microcápsulas é controlado pela taxa de agitação. Quando à taxa de agitação aumenta, o diâmetro da cápsula diminui. Além disso, a microcápsula obtida tinha uma membrana lisa interna e uma superfície externa 'rugosa', o que foi atribuído a um excesso de cloreto de amônio e um valor menor de $\mathrm{pH}$ inicial. Isso também foi observado por Fan et al. [14], que avaliaram o efeito do valor inicial de $\mathrm{pH}$, concentração de surfactante e de ureia-formaldeído na síntese de microcápsulas de PUF. Os autores observaram que um valor de inicial de $\mathrm{pH}$ em torno de 4,5 faz com que as microcápsulas tenham uma superfície mais lisa, e que a adição de cloreto de amônio causa uma queda substancial no valor do $\mathrm{pH}$ durante a reação, aumentando a deposição de nanopartículas na superfície externa da microcápsula [15]. Jin et al. [16] fizeram uma síntese de microcápsulas ocas de PUF e também microcápsulas preenchidas com resina epóxi e outras com o endurecedor da resina. Com um valor de $\mathrm{pH}$ constante $(\mathrm{pH}=2)$ e, utilizando uma agitação de $800 \mathrm{rpm}$, foram obtidas microcápsulas com uma superfície externa lisa, sem a presença de nanopartículas. O diâmetro para as microcápsulas ocas foi de $220 \mu \mathrm{m}$ e para as microcápsulas preenchidas com a resina epóxi e o seu endurecedor foram de $113 \pm 48 \mu \mathrm{m}$ e $117 \pm 32 \mu \mathrm{m}$, respectivamente.

Miguel et al. [6] produziram microcápsulas de PUF preenchidas com óleo de linhaça. Eles testaram a microencapsulação em um estágio (sem pré-polimerização) e com dois estágios (com pré-polimerização). Durante a microencapsulação por um estágio, o pH inicial em 3,5 foi reduzido para 1,6 durante a síntese, observando-se a presença de nanopartículas de PUF que precipitaram e se depositaram na superfície da microcápsula. Os autores tentaram evitar a formação de nanocápsulas, realizando a síntese da PUF sem a presença do surfactante. No entanto, cápsulas frágeis e de formatos irregulares foram obtidas [6].

O objetivo desse trabalho foi avaliar a morfologia e o diâmetro de microcápsulas de PUF por variações na quantidade de octanol utilizadas na síntese. As microcápsulas ocas e preenchidas foram caracterizadas por Microscopia Ótica (MO), Microscopia Eletrônica de Varredura de Efeito de Campo (FEGSEM), Espectroscopia no Infravermelho por Transformada de Fourier (FTIR) e Análise Termogravimétrica (TGA).

\section{MATERIAIS E MÉTODOS}

\subsection{Materiais}

Ureia, formaldeído (37\%, solução aquosa), resorcinol, lauril sulfato de sódio (LSS), octanol, cloreto de amônio, ácido clorídrico (37\%) e acetona (P.A) foram adquiridos da Vetec (Santa Catarina, Brasil). Todos os materiais foram utilizados como recebidos.

\subsection{Síntese das microcápsulas de PUF}

Foram sintetizadas microcápsulas ocas de PUF, em uma suspensão coloidal entre água-ar, seguindo os procedimentos descritos por BROWN et al. [17] e BLAISZIK et al. [18] com alguns parâmetros modificados por WEIHERMANN [19], como o tipo de surfactante e taxa de agitação. Primeiramente, $200 \mathrm{~mL}$ de água deionizada e $0,4 \mathrm{~g}$ de surfactante (LSS) foram adicionados em vaso reacional de $500 \mathrm{~mL}$ (Figura 1(a)) que foi colo- 
cado dentro de um banho termostático à temperatura ambiente $\left(20^{\circ} \mathrm{C}-24^{\circ} \mathrm{C}\right)$. Para formação das bolhas de ar foi utilizado um agitador mecânico digital, marca FISA, modelo 713D e uma pá com hélices móveis (Figura 1 (b)). Foram adicionados 5,00 g de ureia, 0,5g de cloreto de amônio e 0,5 g de resorcinol como agentes de reticulação, sob agitação em $800 \mathrm{rpm}$ e a temperatura do banho que estava em $25^{\circ} \mathrm{C}$ foi ajustada para $55^{\circ} \mathrm{C}$. O pH da solução foi ajustado para 3,5 utilizando-se uma solução de $\mathrm{HCl} \mathrm{0,1} \mathrm{mol/L,} \mathrm{sendo} \mathrm{verificado} \mathrm{através} \mathrm{de}$ um pHmetro (OAKTON, 510 series). Para eliminar o excesso de bolhas foram adicionadas diferentes quantidades de gotas de octanol (0; 4 e 15 gotas), conforme Tabela 1. Após 10 minutos, foram adicionados 12,67g de formaldeído (37\%) e a emulsão permaneceu sob agitação por 4 h e após esse período, resfriada até a temperatura ambiente, filtrada sob vácuo e seco por $48 \mathrm{~h}$ à temperatura ambiente.

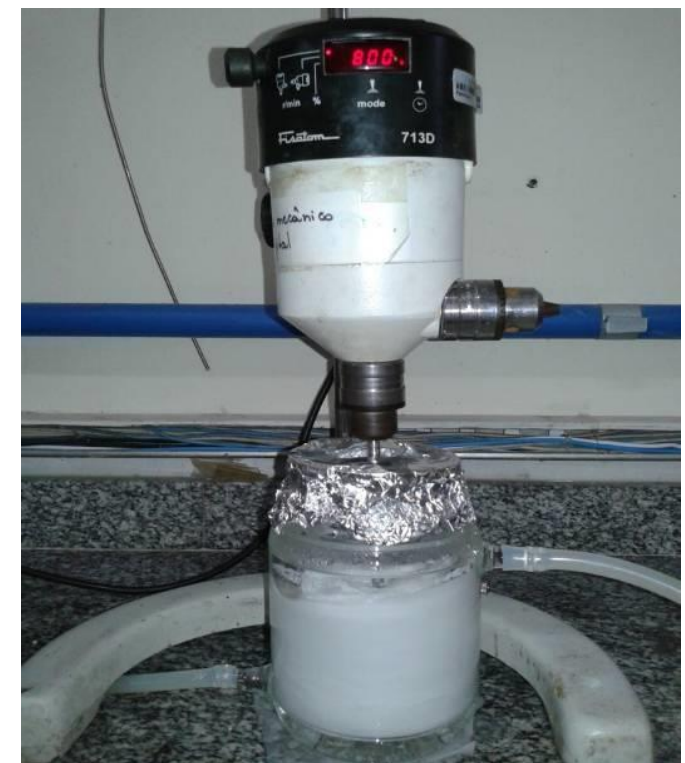

Figura 1: (a)Vidraria encamisada, utilizada como vaso reacional para a síntese das microcápsulas de PUF (b) modelo da pá de hélices móveis utilizada nas sínteses.

Tabela 1: Variação da quantidade de octanol na síntese das microcápsulas de PUF.

\begin{tabular}{c|c|c}
\hline VARIAÇÃO & OCTANOL $(\mathbf{m L})$ & OCTANOL $(\mathrm{mol} / \mathbf{L})$ \\
\hline I & 0 & 0 \\
\hline II & 0,0533 & $1,96.10^{-3}$ \\
\hline III & 0,2183 & $8,02.10^{-3}$ \\
\hline
\end{tabular}

\subsection{Filtração das microcápsulas}

Após as microcápsulas secarem, o pó obtido foi novamente disperso em água. As microcápsulas ocas permaneceram na parte superior da suspensão, enquanto que um pó branco permaneceu no fundo do béquer. A parte superior foi filtrada com água deionizada sob vácuo e seca por 48 h á temperatura ambiente. A amostra foi chamada de M1. A parte inferior foi filtrada nas mesmas condições e foi chamada M2. Posteriormente ambas foram analisadas em um microscópio ótico.

\subsection{Microscopia ótica}

Microscopia ótica (MO) foi realizada em um Olympus modelo CX31. As microcápsulas ocas ou preenchidas $(\sim 0,3 \mathrm{~g})$ foram dispersas em água $(\sim 40 \mathrm{~mL})$ e uma pequena alíquota colocada em uma placa de vidro, sem cobertura, e observado. Foram feitas imagens com magnificação de 10x e 20x. Posteriormente, o diâmetro de 100 microcápsulas foi medido usando o software ImageJ.

\subsection{Microscopia eletrônica de varredura de efeito de campo (FEG)}

A microscopia eletrônica de varredura de efeito de campo (FEGSEM) utilizando o equipamento marca JEOL, modelo JSM 6701F foram realizadas para avaliação da morfologia das microcápsulas. 


\subsection{Espectroscopia no Infravermelho por Transformada de Fourier (FTIR)}

As análises de FTIR foram realizadas em um espectrofotômetro da marca Perkin- Elmer, modelo Spectrum One B, tendo sido realizadas 16 varreduras na região espectral de 4000 a $600 \mathrm{~cm}^{-1}$, com resolução de $4 \mathrm{~cm}^{-1} \mathrm{e}$ utilizando o modo de refletância total atenuada (ATR).

\subsection{Termogravimetria (TG)}

A estabilidade térmica das microcápsulas ocas e preenchidas foi analisada utilizando-se um equipamento da marca NETZSCH, modelo STA 449C-JUPTER, com taxa de aquecimento de $10^{\circ} \mathrm{C} / \mathrm{min}$ em atmosfera de $\mathrm{N}_{2(\mathrm{~g})}$ da temperatura ambiente $\left(25^{\circ} \mathrm{C}\right)$ até $600^{\circ} \mathrm{C}$.

\section{RESULTADOS}

\subsection{Morfologia das microcápsulas}

Microcápsulas de PUF foram sintetizadas a partir da variação da quantidade de octanol, que é frequentemente utilizado para a diminuição de bolhas ('antifoam'). Para avaliar a formação das microcápsulas, aspectos morfológicos e o diâmetro médio, foram registradas imagens de MO e FEGSEM do material obtido. A Figura 2(a) mostra uma imagem de MO com a formação de muitas microcápsulas de formatos esféricos e irregulares (variação I). Também houve polimerização da ureia-formaldeído (UF) como um aglomerado, como mostra a Figura 2(b). Na Figura 2(c) através da imagem FEGSEM é possível observar que a microcápsula possui nanocápsulas aderidas em sua superfície. Uma ampliação dessas microcápsulas é mostrada na Figura 2(d), em que a espessura da parede da microcápsula possui 0,57 $\mu \mathrm{m}$. Durante a síntese de microcápsulas de PUF, o pH foi ajustado para 3,5 e conforme as reações vão ocorrendo o pH tem um declínio, chegando aproximadamente em 1,6. Quando o valor do pH é menor que 3, há a formação de nanocápsulas que se aglomeram na superfície da cápsula, deixando-a mais rugosa e aumentando sua espessura. Em todas as variações, foi observada a formação de nanocápsulas em volta da microcápsula. Essas nanocápsulas aumentam a espessura da parede, aumentando a força e durabilidade da cápsula [6] [14] [15]. O diâmetro mais frequente foi de $36 \mu \mathrm{m}$, conforme dados da Figura 3(a).

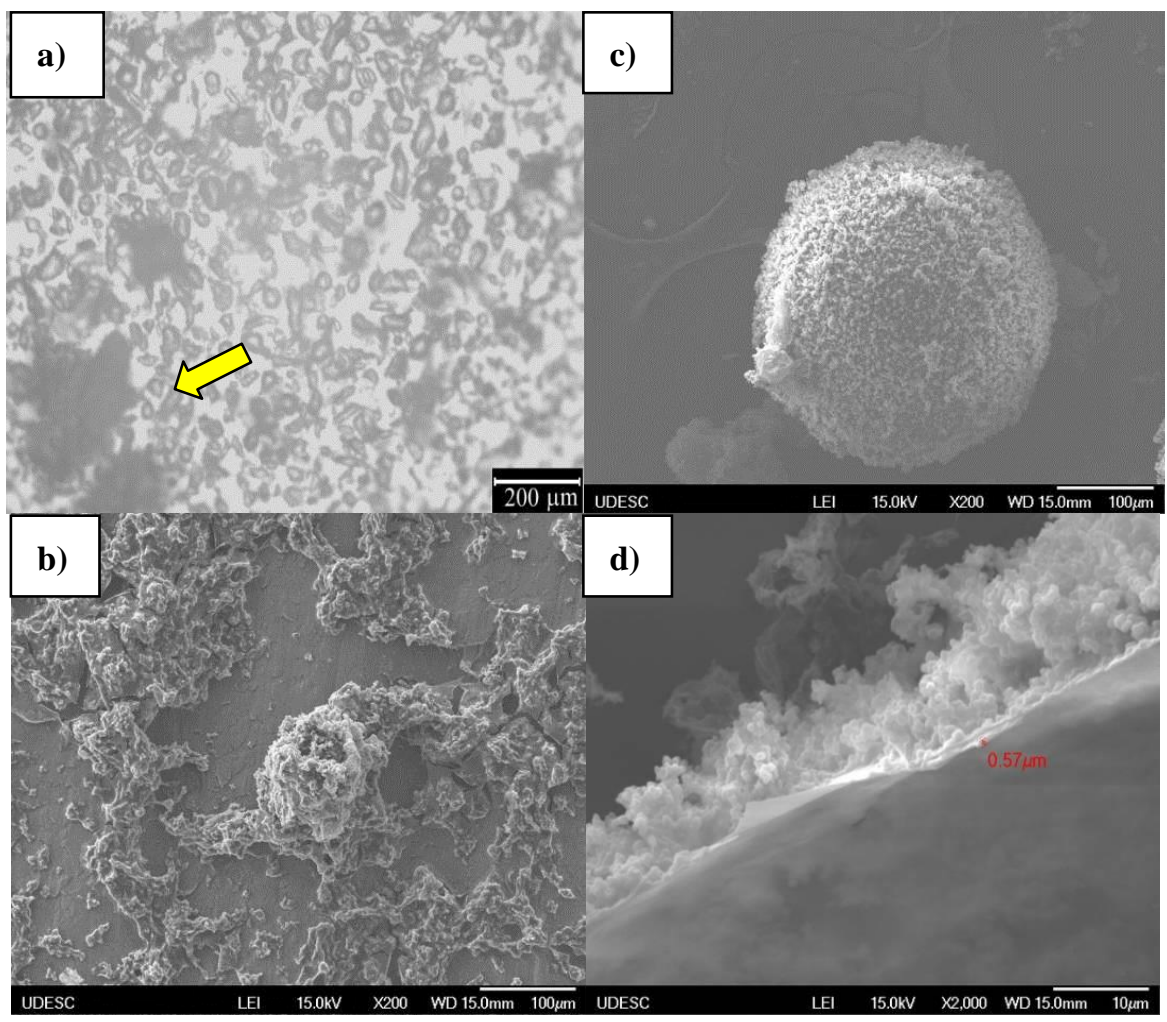

Figura 2: (a) imagem de MO das microcápsulas da variação I e (b) imagem de FEGSEM da 'espuma', um aglomerado de UF, que aparece como uma seta amarela na Figura 2(a), (c) imagem de FEGSEM de uma microcápsula da variação I e (d) medida da espessura de uma das microcápsulas, mostrando o valor de $0,57 \mu \mathrm{m}$. 

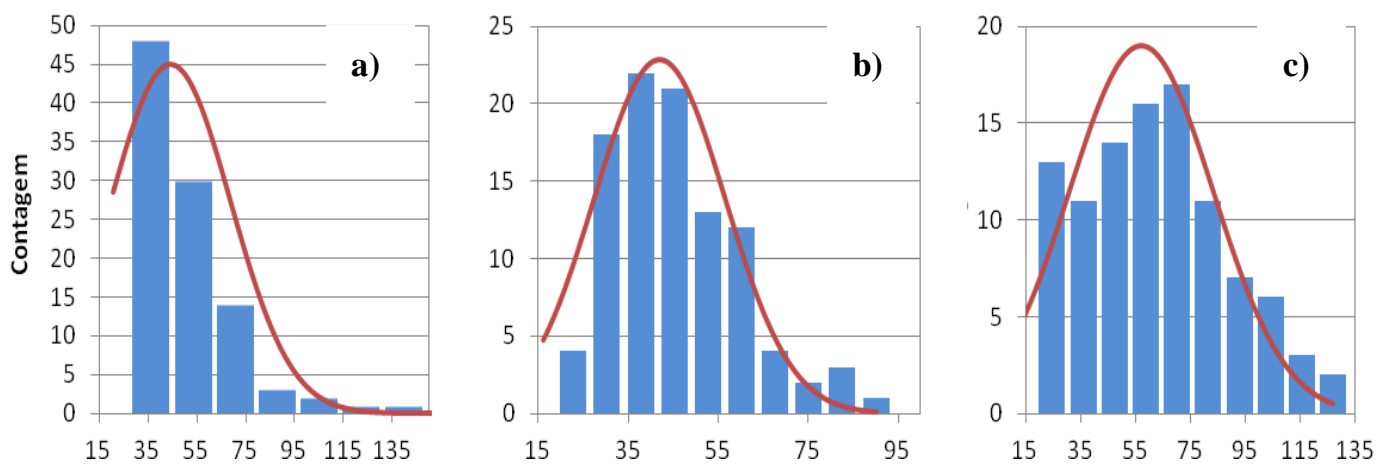

Diâmetro das microcápsulas $(\mu \mathrm{m})$

Figura 3: Distribuição de tamanho das microcápsulas sintetizadas pela (a) variação I (b) variação II (c) variação III.

A quantidade de octanol utilizado na variação II é semelhante à encontrada na literatura [6]. Nesta variação, microcápsulas de formato esférico foram produzidas, como mostra a Figura 4(a) e (b). No entanto, as microcápsulas apresentaram uma superfície mais rugosa, quando comparadas com a variação I. Essas nanocápsulas, que são responsáveis pelo aumento da rugosidade, aparecem como áreas mais escuras em volta das cápsulas na Figura 4(a).

Além disso, essa variação apresentou uma larga distribuição de diâmetros, conforme Figura 3(b). O diâmetro mais frequente foi de 37,8 m, muito próximo ao valor da Variação I. Resultados semelhantes também foram reportados na literatura para uma taxa de agitação similar [9] [19].

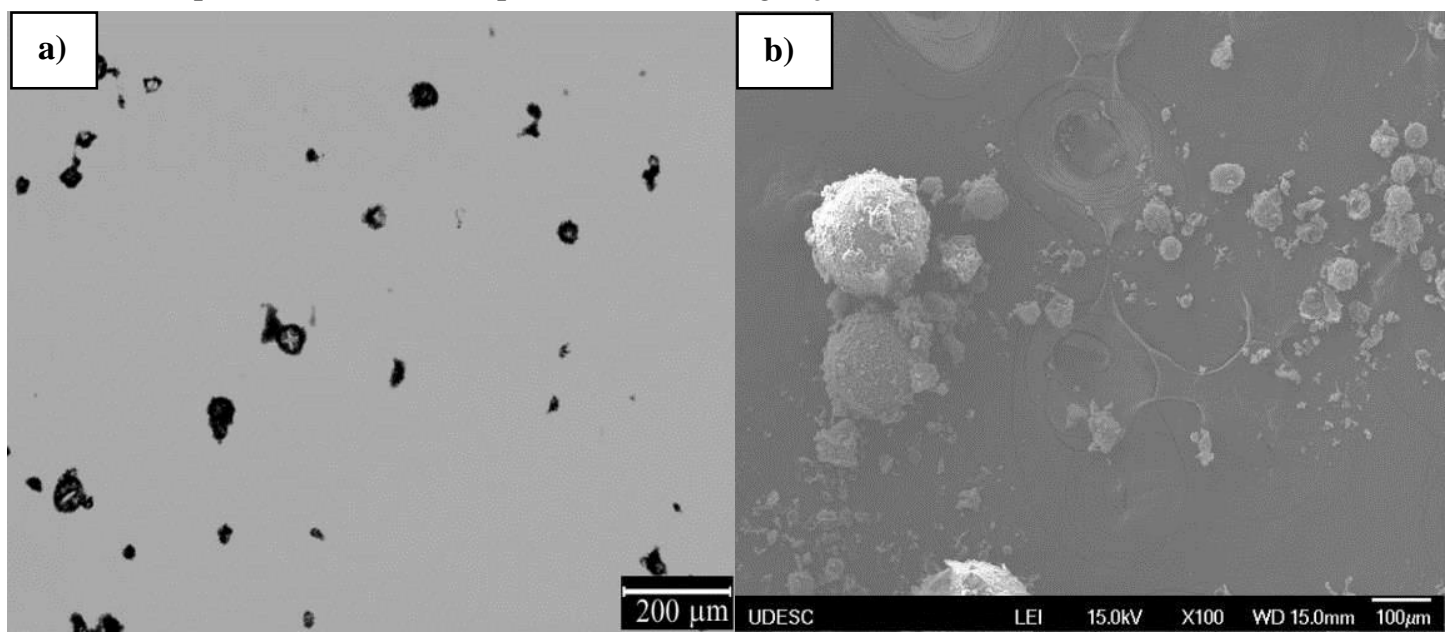

Figura 4: (a) imagem de MO das microcápsulas da variação II (b) imagem de FEGSEM de uma microcápsula da variação II.

Adicionando-se um excesso de álcool octílico (variação III), observou-se que a quantidade de bolhas de ar diminuiu drasticamente quando a temperatura de reação foi atingida $\left(\sim 55^{\circ} \mathrm{C}\right)$. As microcápsulas apresentam uma morfologia mais rugosa que as Variações I e II, evidente na Figura 5(a) e (b). Foram obtidas microcápsulas com diâmetros maiores do que a Variação I e II, em que o diâmetro mais frequente foi de 70 $\mu \mathrm{m}$ (Figura 3(c)). Também houve a deposição de nanocápsulas tanto na superfície da microcápsula, quanto aglomerados de nanocápsulas em emulsão, como pode ser observado pela Figura 5(a) e também pela Figura $5(\mathrm{~b})$.

A menor formação de espuma na Variação I e III pode ser atribuída ao fato do álcool (octanol) possuir uma maior capacidade de reduzir a tensão superficial do que o LSS, criando um ponto de fragilidade na bolha. Esse ponto de fragilidade pode ser, por exemplo, uma mudança pontual de espessura. Essa mudança aumenta a tensão superficial local, pois o surfactante está em menor concentração [20]. Pelo efeito GibbsMarangoni [21], esse aumento da tensão superficial local causa um deslocamento interno das moléculas do surfactante para reestabelecer a tensão superficial e evitar a mudança da espessura, a fim de impedir o rompimento da cápsula, porém, levando a sua instabilidade [22]. 


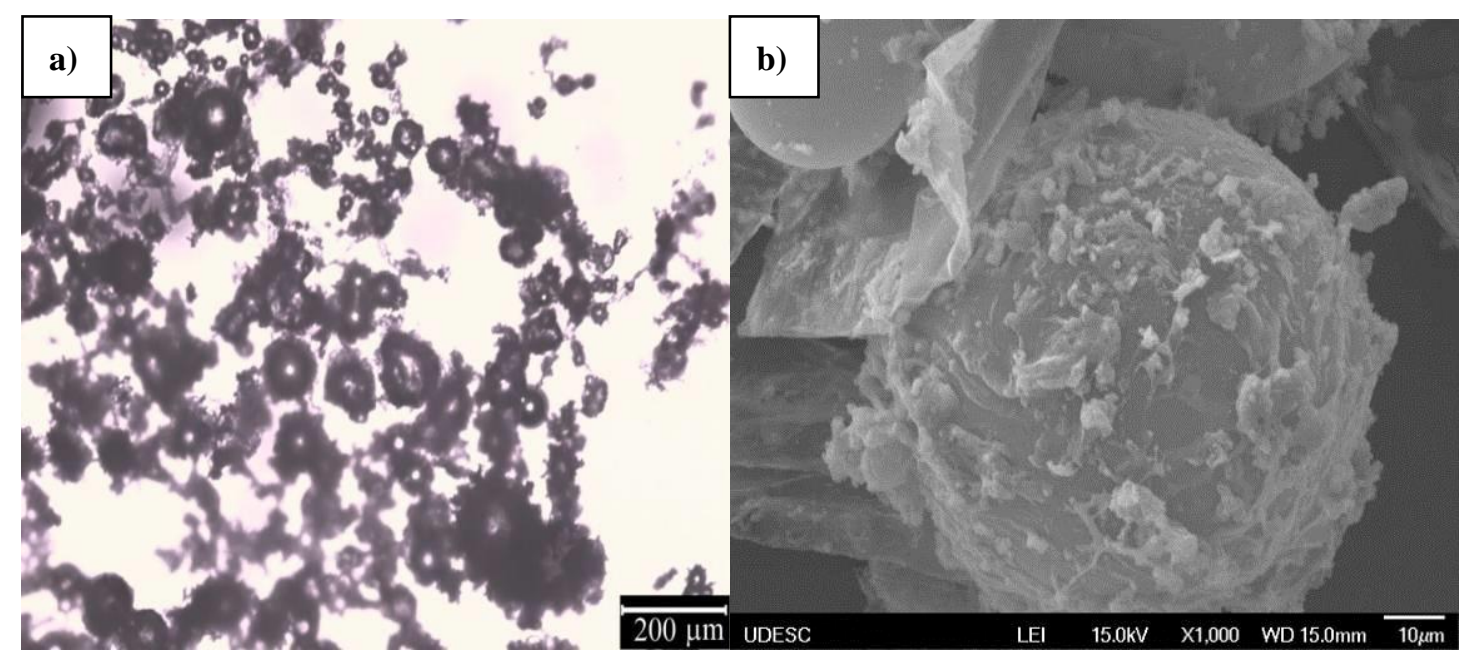

Figura 5: (a) OM das microcápsulas preparadas pelas descrições da variação III e (b) imagens de FEGSEM de uma microcápsula da imagem (a).

Com o intuito de separar o material que não reagiu e microcápsulas rompidas, as microcápsulas da variação II foram novamente dispersas em água e deixadas em repouso por 48h. Como já observado em outros trabalhos [6] [14], as microcápsulas sem defeitos flutuaram e foram novamente filtradas. Após secarem, o resultado final foi um pó fino e bem solto. O material que decantou também foi filtrado, e seu aspecto final foi um pó compacto.

\subsection{Espectroscopia no infravermelho por transformada de Fourier (FTIR)}

O espectro de FTIR das microcápsulas de PUF da Variação II é apresentado na Figura 6, e as bandas e atribuições são apresentadas na Tabela 2. Os picos característicos como o estiramento da ligação N-H a 1548 $\mathrm{cm}^{-1}$, o estiramento da ligação $\mathrm{C}=\mathrm{O}$ a $1625 \mathrm{~cm}^{-1}$ e o estiramento da ligação $\mathrm{C}-\mathrm{N}$ a $1230 \mathrm{~cm}^{-1}$ confirmam a formação de poli(ureia-formaldeído). $\mathrm{O}$ grupo $\mathrm{OH}$ aparece como uma banda larga em $3320 \mathrm{~cm}^{-1}$, associada a adsorção de água [9] [19].

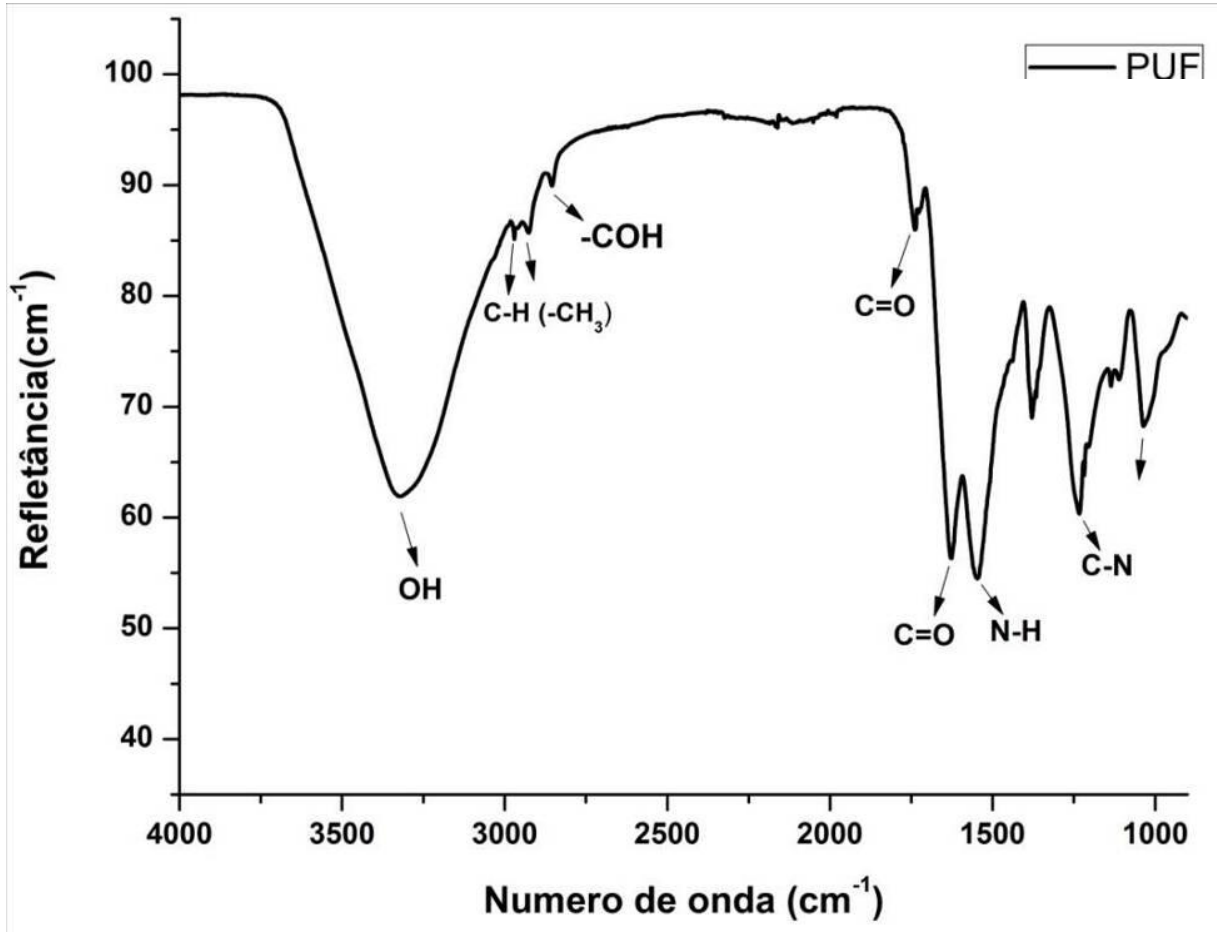

Figura 6: Espectro de FTIR com as bandas características da microcápsula de PUF. 
Tabela 2: Principais grupos e suas atribuições para a microcápsula de Poli(ureia-formaldeído) (PUF) .

\begin{tabular}{c|c|c}
\hline Grupo & Frequência $\left(\mathbf{c m}^{-1}\right)$ & Atribuição \\
\hline $\mathrm{O}-\mathrm{H}$ & 3320 & $v, \mathrm{~L}$ \\
\hline $\mathrm{CH}\left(-\mathrm{CH}_{3}\right)$ & 2926 e 2963 & $v, \mathrm{~m}-\mathrm{F}$ \\
\hline $\mathrm{COH}$ & 2854 & $v, \mathrm{f}-\mathrm{m}$ \\
\hline $\mathrm{N}-\mathrm{H}$ & 1548 & $v, \mathrm{f}-\mathrm{m}$ \\
\hline $\mathrm{C}=\mathrm{O}$ & 1625 e 1738 & $v, \mathrm{~F}$ \\
\hline $\mathrm{CH}_{3}$ & 1380 & $\delta$ sim,m \\
\hline \multirow{2}{*}{$\mathrm{C}-\mathrm{N}$} & 1230 & $v, \mathrm{f}-\mathrm{m}$ \\
\cline { 2 - 3 } & 1036 & $v, \mathrm{f}-\mathrm{m}$ \\
\hline
\end{tabular}

$v$ =estiramento; $\delta=$ deformação; ass= assimétrica; sim= simétrica; f=fraca; m=média; $\mathrm{F}=$ forte [9][19]

\subsection{Termogravimetria (TG)}

A Figura 8 mostra as curvas termogravimétricas para amostras de microcápsulas ocas, realizadas com o objetivo de avaliar a estabilidade térmica. A Tabela 3 apresenta a temperatura de degradação inicial $\left(\mathrm{T}_{\text {onset }}\right)$ e final $\left(\mathrm{T}_{\text {endset }}\right)$, assim como a temperatura de degradação $\left(\mathrm{T}_{\text {peak }}\right)$ da microcápsula oca da primeira filtração (M1) e do material da segunda filtração (M2), conforme item 2.3.

A curva da amostra M1 apresentam três intervalos de perda de massa: o primeiro em $87^{\circ} \mathrm{C}$ com $5 \%$ de perda de massa, relativa à eliminação de água. A segunda em $267^{\circ} \mathrm{C}$ é atribuída à decomposição da poli(ureia-formaldeído), com $47 \%$ de perda de massa. Até $600^{\circ} \mathrm{C}$ ainda havia um resíduo de $18 \%$. A curva da amostra M2 apresenta praticamente os mesmos valores de $\mathrm{T}_{\text {peak }}$, porém, com uma menor perda de massa. $\mathrm{O}$ $\mathrm{T}_{\text {peak }} \mathrm{em} 264^{\circ} \mathrm{C}$ apresentou $11 \%$ e o resíduo foi maior em relação à M1. As microcápsulas deste trabalho possuem maior estabilidade térmica quando comparadas com outros trabalhos da literatura [6] [9] [14] [23] [24].

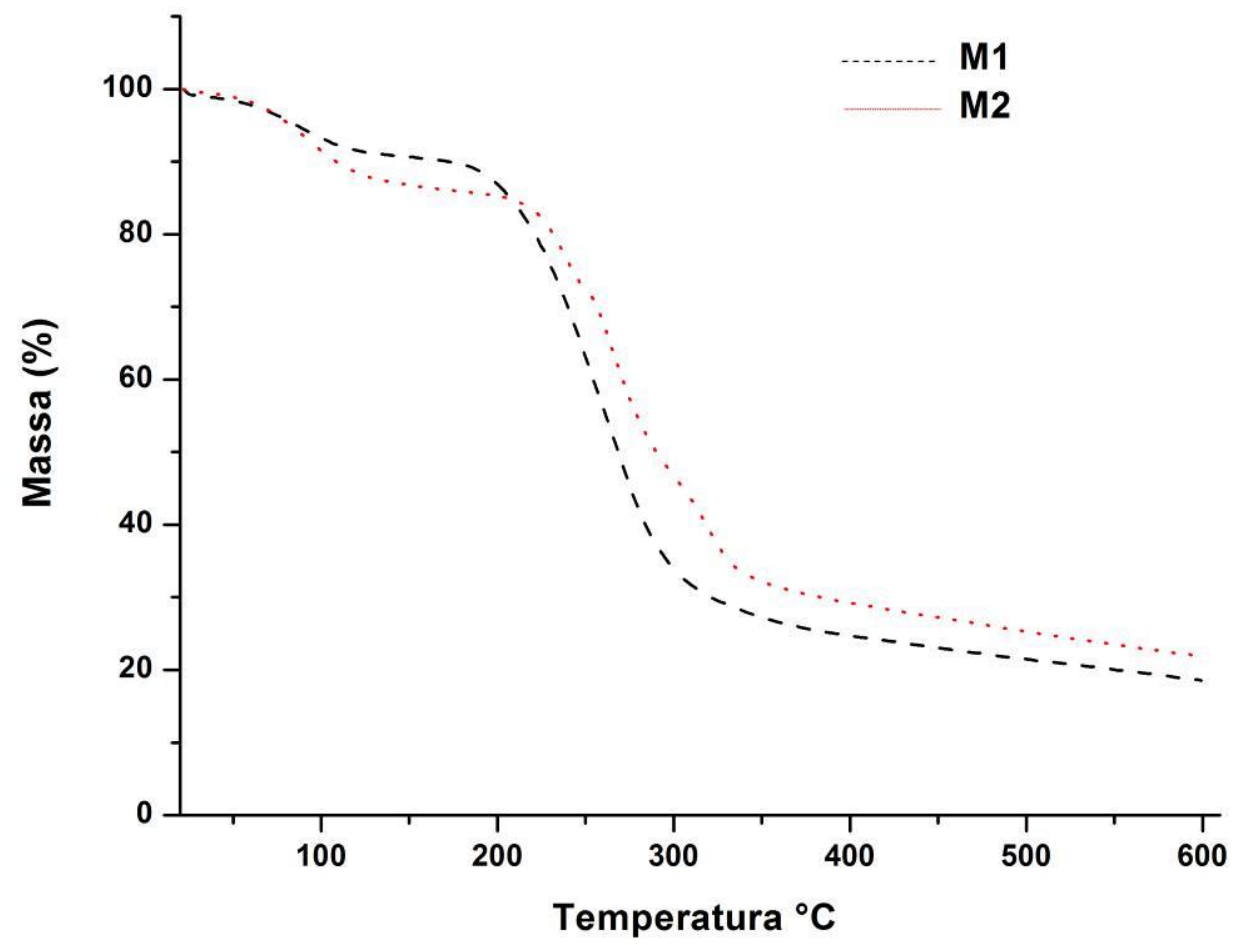

Figura 7: Curvas de TG para as microcápsulas (M1) e para o sedimento (M2). 
Tabela 3: Temperaturas de degradação inicial $\left(T_{\text {onset }}\right)$, pico de degradação $\left(T_{\text {peak }}\right)$ e degradação final $\left(T_{\text {endset }}\right)$ e intervalos de perda de massa para as microcápsulas (M1 e M2).

\begin{tabular}{c|c|c|c}
\hline Amostra & $\mathbf{T}_{\text {peak }}\left({ }^{\circ} \mathbf{C}\right)$ & $\mathbf{T}_{\text {onset- }} \mathbf{T}_{\text {endset }}\left({ }^{\circ} \mathbf{C}\right)$ & $\%$ massa \\
\hline \multirow{2}{*}{ M1 } & 87 & $50-125$ & 5 \\
\cline { 2 - 4 } & 267 & $179-323$ & 49 \\
\hline \multirow{2}{*}{ M2 } & 87 & $43-127$ & 5 \\
\cline { 2 - 4 } & 264 & $206-350$ & 36 \\
\hline
\end{tabular}

\section{CONCLUSÕES}

A morfologia e o diâmetro de microcápsulas de PUF variando-se a quantidade de octanol na síntese foram avaliados. Microcápsulas de formatos irregulares foram obtidas pela síntese com ausência de octanol, além da formação de aglomerados de ureia-formaldeído. Já a utilização de uma quantidade maior de octanol (Variação III) diminuiu a quantidade de bolhas de ar durante a síntese e aumentou o diâmetro frequente das microcápsulas, assim como a rugosidade da parede, pelo aumento da formação de nanocápsulas em emulsão. $\mathrm{O}$ aumento da rugosidade das microcápsulas pela deposição de nanocápsulas em sua superfície também é atribuída a um declínio do $\mathrm{pH}$ durante a síntese.

Utilizando uma menor quantidade de octanol (Variação II), houve a formação de microcápsulas mais esféricas com uma superfície menos rugosa quando comparadas com a Variação III. As análises de FTIR confirmam as bandas características para as microcápsulas de PUF, enquanto as curvas de TG mostram uma estabilidade térmica adequada para aplicações em materiais poliméricos autorregeneráveis.

\section{BIBLIOGRAFIA}

[1] VIJAYAN, P., ALMAADEED, M., “Containers' for self-healing epoxy composites and coating:Trends and advances", Express polymer Letters, v. 10, pp. 506-524, 2016.

[2] DONG YANG, W., MEURE, S., E SOLOMON, D., "Self-healing polymeric materials: A review of recent developments", Progress in polymer science, v. 33, n.5, pp. 479-522, 2008.

[3] TSANGOURI, E., AGGELIS, D., E HEMELRIJCK, D. V., "Quantifying thermoset polymers healing efficiency: A systematic review of mechanical testing”, Progress in Polymer Science, v. 49-50, pp. 154-174, 2015.

[4] VAN DER ZWAAG, S., Self Healing Materials: An alternative Approach to 20 Centuries of Materials Science, Dordrecht, Springer-Verlag, 2007.

[5] BLAISZIK, B., KRAMER, S.L.B., OLUGEBEFOLA, S.C., et al., "Self-Healing polymers and composites”, Annu.Rev.Mater.Res., v. 40, pp. 179-211, 2010.

[6] Miguel, M. D. L. P., OLLIER, R., ALVAREZ, V., et al., "Effect of the preparation method on the structure of linseed oil-filled poly(urea-formaldehyde) microcapsules", Progress in Organic Coatings, v. 97 , pp. 194-202, 2016.

[7] KNOP, W. R., MEIER, M. M., PEZZIN, S. H., "Preparação e caracterização de microcápsulas de poli (ureia-formaldeído) preenchidas com diciclopentadieno”. Matéria, v. 19, p. 266-273, 2014.

[8] SUN, D., AN, J., WU, G., et al., "Double-layered reactive microcapsules with excellent thermal and nonpolar solvente resistence for self-healing coatings", Journal of Materials Chemistry A, v. 3, pp. 4435-4444, 2015.

[9] CHOWDHURY, R. A., HOSUR, M.V., NURUDDIN, M.D., et al., "Self-healing epoxy composites: preparation,characterization and healing performance, J.Mater Res Technol, v. 4, pp. 33-43, 2015.

[10] WHITE, S.R., SOTTOS, N.R., GEUBELLE, P.H., et al, "Autonomic healing of polymer composites", Nature, v. 409, pp. 794-797, 2001.

[11] BROWN, E., SOTTOS, N.R., WHITE, S.R., et al., "Fracture testing of a self-healing polymer nanocomposite", Exp Mech, v. 42, pp. 372-379, 2002.

[12] JUNG, D., HEGEMAN, A., SOTTOS, N.R., et al., "Self-healing composites using embedded microspheres", In: em USA: ASME International Mechanical Engineering Congress, Dallas, 1997.

[13] MANGUN, C., MADER, A.C., SOTTOS, N.R, et al., "Self-healing of a high temperature cured epoxy 
using poly(dimethylsiloxane)chemistry", Polymer, v. 51, pp. 4063-4068, 2010.

[14] FAN, C. E., ZHOU, X. "Influence of operating conditions on the surface morphology of microcapsules prepared by in situ polymerization", Colloids and Surfaces A: Physicochemical and Engineering Aspects, v. 363, pp. 49-55, 2010.

[15] FAN, C., TANG, J., E ZHOU, X., "Role of Ammonium Chloride in Preparing Poly(urea-formaldehyde) Microcapsules Using One-Step Method", Journal Applied Polymer Science, v. 129, pp. 2848-2856, 2013.

[16] JIN, H., MANGUN, C.L., STRADLEY, D.S., et al., "Self-healing thermoset using encapsulated epoxyamine healing chemistry", Polymer, v. 53, pp. 581-587, 2012.

[17] BROWN, E., KESSLER, M.R., SOTTOS, N.R., et al., "In situ poly(ureaformaldehyde)microencapsulation of dicyclopentadiene", Journal of microencapsulation, v. 20, pp. 719-730, 2003.

[18] BLAISZIK, B., SOTTOS, N.R., WHITE, S.R, et al., "Nanocapsules for self-healing materials", Composites Science and Technology, vol. 68, pp. 978-986.

[19] WEIHERMANN, W. R. K., Desenvolvimento de um sistema epoxídico autorregenerável utilizando polidimetilsiloxano amino funcional, Tese de D.Sc., UDESC, 2015.

[20] TREINER, C., KHODJA, A. A., FROMON, M. "Micellar Solubilization of 1-Pentanol in Binary Surfactant Solutions: A regular Solution Approach", Langmuir, v. 3, pp. 729-735, 1987.

[21] TADROS, T. Emulsion Formation, Stability, and Rheology, Emulsion Formation and Stability, 1aedição ed., Wiley-VCH Verlag GmbH \& Co. KGaA, 2013, pp. 1-72.

[22] SILVA, J. D. F., SILVA, Y.P., PIATNICKI, C.M.S., "Microemulsões: componentes, características, potencialidades em química de alimentos e outras aplicações", Quim. Nova, v. 38, n. 9, pp. 1196-1206, 2015.

[23] BOLIMOWSKI, P. A., BOND, I. P., WASS, D. F., "Robust synthesis of epoxy resin-filled microcapsules for application to self-healing materials", Phil.Trans.R.Soc.A, v. 374, n.4, 2015.

[24] HENGHUA, J., MANGUN, C. L., GRIFFIN, A.S., et al., "Thermally Stable Autonomic Healing in Epoxy using a Dual-Microcapsule System”, Advanced materials, v. 15, pp. 282-287, 2013. 